\title{
TECHNOLOGY OF ELECTROSPARK HARDENING OF CUTTING SURFACE OF FEED MIXER KNIVES
}

\author{
Sergey Strebkov, Alexey Slobodyuk, Andrey Bondarev \\ Belgorod State Agricultural University named after V. Gorin, Russia \\ serwastr@gmail.com, asp122@yandex.ru, av.bondarev@gmail.com
}

\begin{abstract}
The research is aimed at ensuring the durability of the knives of a feed mixer-distributor with a vertical cutting-chopping and mixing scheme of feed preparation. The analysis of the wear process of the feed mixer knife found that the loss of performance occurs due to the violation of the geometry of the working edge of the knife in the course of mainly abrasive wear. The required level of durability can be achieved by reducing the wear rate. Strengthening the front surface of the knife cutting teeth increases the resource of the working body. Strengthening by electrospark alloying is considered as one of the technological methods. At the same time, an increase in the hardness of the working surface of the edge is achieved, while providing both fatigue and impact strength. When developing the technology, a comparison was made of various materials for forming a coating. The optimal rods are made of steel R5M6 (HSS) and a surfacing electrode T-590. The development of the operating parameters of coating deposition on the BIG-4 installation showed that the oscillation frequency of the electrode and the pulse energy have the greatest influence on the quality of the resulting coating. A microstructural analysis of the coating obtained during alloying in terms of microhardness and porosity has been carried out. For practical use, a technology has been developed and applied for hardening the knives of the feed mixer made of grade 45 carbon steel, which have acquired wear resistance at the level of knives made of $65 \mathrm{G}$ manganese steel spring. The results of life tests of hardened working bodies in the production conditions of a company engaged in dairy cattle breeding are presented, which showed an increase in the resource of the feed mixer knives by $67 \%$. Conclusions are made about the expediency of using the developed technology to obtain a hardening coating on the cutting edge of the feed mixer knife.
\end{abstract}

Keywords: durability; wear; electrospark alloying.

\section{Introduction}

Feeding is one of the most important things among the many operations for cattle keeping. The modern biologically based daily diet includes roughage with low moisture and high fiber, succulent (silage), concentrated feeds and special additives.

The task of the farm staff is to prepare the feed in accordance with the given ration. The preparation process includes accurate dosing of ingredients and high-quality mixing, resulting in a mixture with a given granulometric composition.

Currently, on farms, the preparation of feed is carried out mainly using mobile feed mixersdistributors. Mobile feed mixers, depending on their performance, can be equipped with one or more vertical or horizontal augers. To intensify the mixing and grinding of roughage, knives are installed on the augers.

During operation, the knives wear out intensively, which leads to the necessity to replace them. Thus, the knife is a consumable part that needs to be replaced according to the actual condition, based on geometric parameters assessment.

The need for frequent replacement of feed mixer knives leads to downtime, disruption of the schedules of technological processes on the farm, additional financial costs and, as a result, an increase in the cost of production and a decrease in the economic efficiency of the enterprise.

To increase the service life of the knives, it is necessary to harden the surface layer or apply a coating with sufficiently high physical and mechanical properties $[1 ; 2]$. One of the most advanced methods of alloying the surface layer is electric spark treatment [3].

The article is devoted to increasing the service life of the working bodies - knives of the feed mixerdistributor with a vertical auger, which, in order to save operating costs, are made of less expensive (and less wear-resistant) steel, but acquire increased operational qualities due to strengthening the front surface of the cutting teeth of the knife by applying a functional coating.

\section{Materials and methods}

The research is aimed at maintaining the knives durability of the feed mixer-distributor with a vertical cutting-grinding and mixing scheme of feed preparation. 
The knife is a replaceable part of the working body of the feed mixer, and it is fixed on a vertical conical auger conveyer and is designed for cutting and mixing coarse feed components. To reduce operating costs, agricultural producers purchase non-original parts and replicas made of less expensive steel with lower wear resistance. Therefore, it is necessary to conduct research on the regularities of the knife wear process.

The loss of performance occurs due to geometry violation of the working edge of the knife as a result of abrasive wear (Fig. 1). Since the parameter of the limit state is the angle of sharpening, the wear process is proposed to be determined by measuring the linear dimensions (Fig. 2) from the base point the mounting hole to the characteristic points - the tops of the teeth $\left(1_{1}, 1_{2}, \ldots 1_{10}\right)$. At the same time, for the convenience of processing and presenting the results we will determine the total distance $L_{n}$ for each $n$ - measurement

$$
L_{n}=\sum_{1}^{10} L_{i},
$$

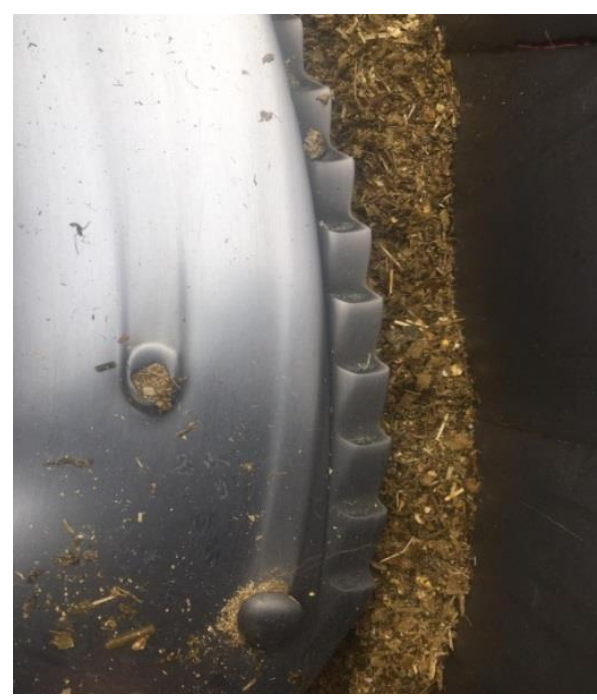

Fig. 1. Worn-out knife of the feed mixer

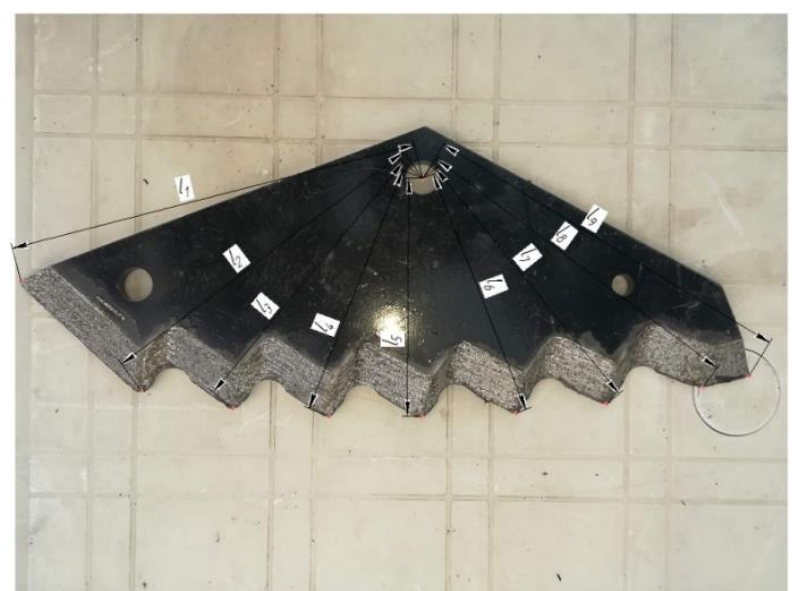

Fig. 2. Scheme of measuring the knife geometry

It is proposed to estimate the integral state of the knife by a dimensionless coefficient

$$
\beta=\frac{L_{n}}{L_{0}},
$$

where $L_{0}-$ is a total distance for the new knife.

The base point is selected in such way that you can take measurements from it without removing the knife from the feed mixer, i.e. during technological pauses in the unit operation.

Measurements were carried out on the farm every 500 tons of the prepared mixture using a sliding calliper SHCC-2-400-0.1 (accuracy is $0.1 \mathrm{~mm}$, class is 1 ).

Obviously, it is possible to provide the necessary level of part durability in question by reducing the wear rate. To reduce the wear intensity with a constant diet of animals (processed components) is possible only by improving the quality of the knife. For this, two options can be implemented - either the use of expensive high-quality wear-resistant steel or the use of functional hardening coatings.

After analyzing the methods of strengthening the working bodies of agricultural machines [4;5], it was found that the greatest effect is given by applying strengthening coatings to the front surface of the knife. In addition, there are several methods of coating: plasma surfacing, supersonic sputtering, surfacing by manual electric arc welding, electric spark processing, physical and chemical effects on the part [6-9].

A comparison of the mentioned above methods by technological and technical, and economic parameters showed that the most appropriate is the use of electric spark processing, due to its cheapness, 
manufacturability, in addition, the use of electric spark processing allows to apply a coating of a given quality without changing the structure of the part's base material.

Thus, as a method of hardening, electric spark treatment of the front surface of the new knife made of steel 45 GOST 1050-2013 is chosen, which allows, in addition to increasing the hardness of the working edge, to increase the fatigue and impact strength.

Hardening of the working surface was carried out according to the following technology. The front surface of the new knife was cleaned of dirt and factory coatings with an abrasive tool, and with the help of a supersonic metal deposition unit DIMET- 405 was activated by a stream of silicon oxide powder. A two-layer coating was applied by electric spark doping. The first layer was made of the minimum thickness with maximum adhesion to the substrate, and the second layer provided increased performance characteristics of the knife.

When choosing materials for strengthening the cutting edge we relied on the research of the manufacturer of the complex for electric spark processing BIG-4 and the research of Zadorozhny R. N. [10].

Due to fact that feed contains components with high acidity (silage), special attention should be paid to the prevention of corrosion degradation of the applied coating in the development of hardening technology. The key parameter in this case is the porosity of the surface layer.

The measurement of the porosity and microhardness of the obtained coatings was carried out on specially prepared samples (a strip of steel 45 GOST 1050-2013) in the course of a series of experiments. The samples were coated according to the above-described technology of coatings from various materials, varying the amplitude current, energy coefficient, and the amplitude of electrode oscillations on the BIG-4 complex.

The analysis of porosity was carried out visually on a metallographic inverted optical microscope GX53F. Microhardness was measured on an automatic microhardness meter DuraScan 20 (Fig. 3). The samples were prepared according to a standard technique using a specialized set of equipment - a Secotom-50 precision cut-off machine, a CitoPress-30 automatic press, and a LaboPol-30 grinding and polishing machine.
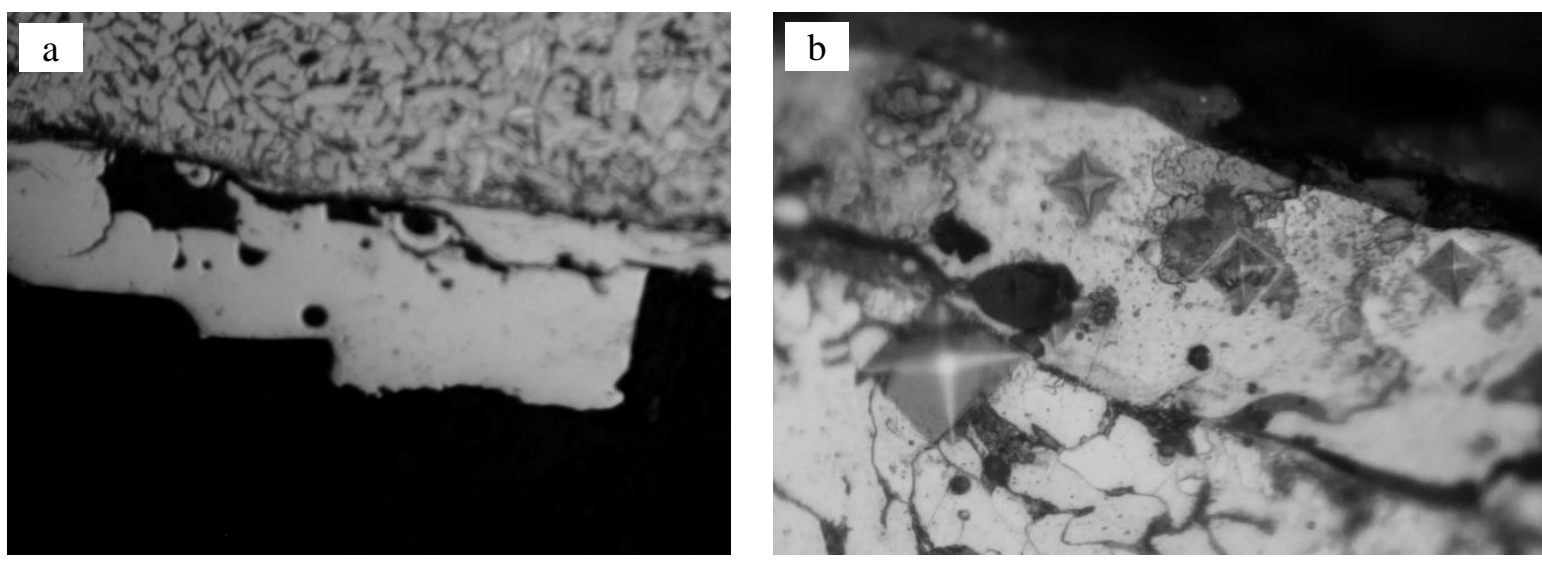

Fig. 3. Comparison of porosity of different samples:

$a$ - coated sample; $b$ - microhardness measurement

\section{Results and discussion}

In the laboratory of restoration of worn parts of the Belgorod State Agrarian University, a technology for strengthening the knives of feed mixers-distributors by electric spark treatment using local cooling of the alloying zone has been developed.

The choice of materials for alloying working bodies operating under conditions of abrasive wear was carried out [11]. Thus, it was found that the best results were shown by coatings based on highcarbon steels with a high content of alloying components and coatings based on hard-alloy inserts.

The front surface of the feed mixer knives was hardened using rods made of high-speed steel R5M6 and T-590 electrodes. 
Processing the results of evaluating the porosity and microhardness of the samples made it possible to obtain the parameters of the technological process of hardening the knives of the feed mixer.

The selected parameters of the technological process make it possible to obtain coatings with a minimum porosity and microhardness in the range of 650-850 HV.

The hardening of the feed mixer knives prepared for coating was carried out in the following order. The first layer of material was applied using a BIG-4 complex in the third mode with an energy coefficient of 0.8 with a minimum amplitude of electrode oscillations (amplitude current $200 \mathrm{~A}$, pulse duration $80 \mu \mathrm{s}$, pulse frequency $600 \mathrm{~Hz}$, pulse energy $0.29 \mathrm{~J}$ ). Then the main layer of the coating material was applied in the fourth mode with an energy factor of 1.0 (peak current $200 \mathrm{~A}$, pulse duration $170 \mu \mathrm{s}$, pulse frequency $420 \mathrm{~Hz}$, pulse energy $0.61 \mathrm{~J}$ ) with maximum amplitude.

We conducted a series of experiments on applying a coating based on high-speed steel P6M5 GOST 19265-73, surfacing electrode T-590 GOST 10051-75 and hard alloys T15K6 and VK8 GOST 3882-74 samples made of low-carbon steel and knives made of structural steel 45 (Fig. 4).

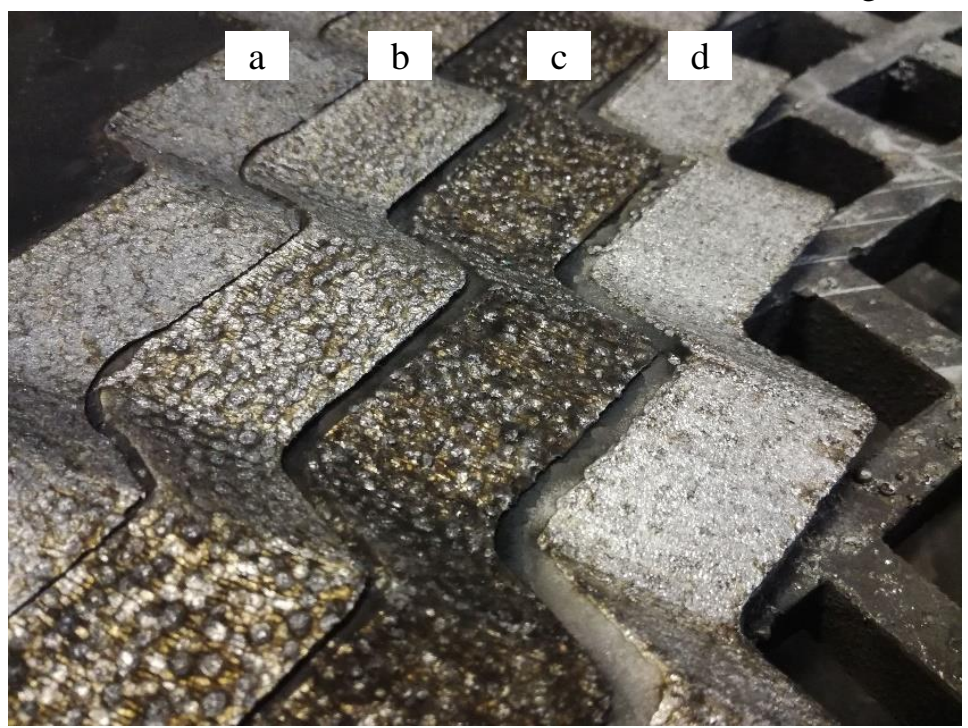

Fig. 4. Knives coated with different materials: a - T15K6 coating; b - P6M5 coating; c - T-590; d - VK8

Analysis of the data obtained on the increment in the mass of the steel sample (Fig. 5), the study of microhardness, porosity and the estimated cost of the resulting coating made it possible to choose rods made of high-speed steel R5M6 (HSS) as the working material of the electrodes.

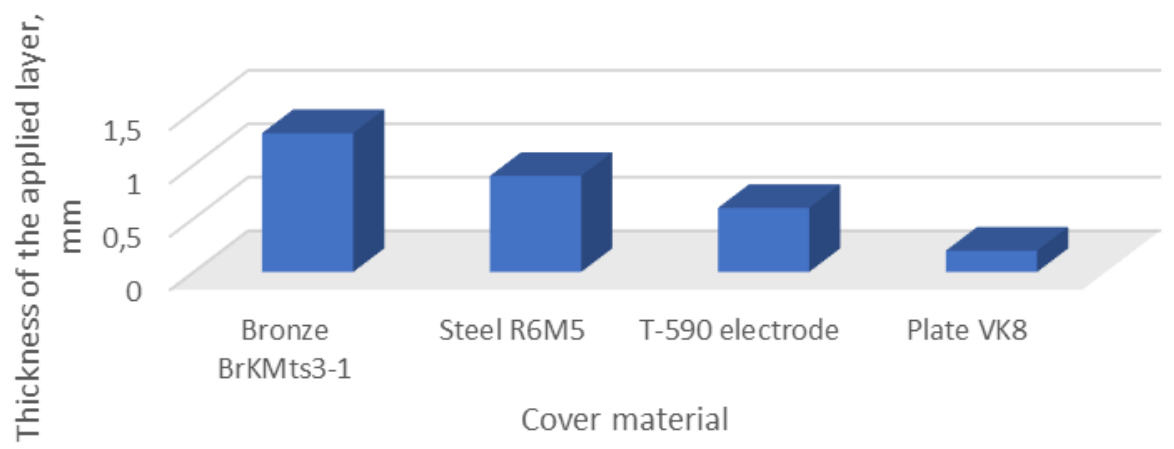

Fig. 5. Maximum thickness of coatings obtained during material processing

In the course of working out the operating parameters of coating application, experimental studies were conducted, which showed that the maximum influence on the quality of the obtained coating is exerted by the frequency of electrode vibrations and the pulse energy, as a result of which the data obtained by Zadorozhnij R. N. during the restoration of the connecting rods of the internal combustion engine were confirmed. 
The analysis of the obtained micro-grinds of the samples showed that the greatest effect on the quality of adhesion and porosity minimization is achieved during electric spark processing with local cooling of the material deposited on the part by a stream of compressed air directed to the processing zone.

After processing, the knives were subjected to operational life testing. The results (Fig. 6) indicate the high wear resistance of the resulting coating, since even after working out the double resource of the base part, the prototypes retained the working geometry within the permissible parameters.

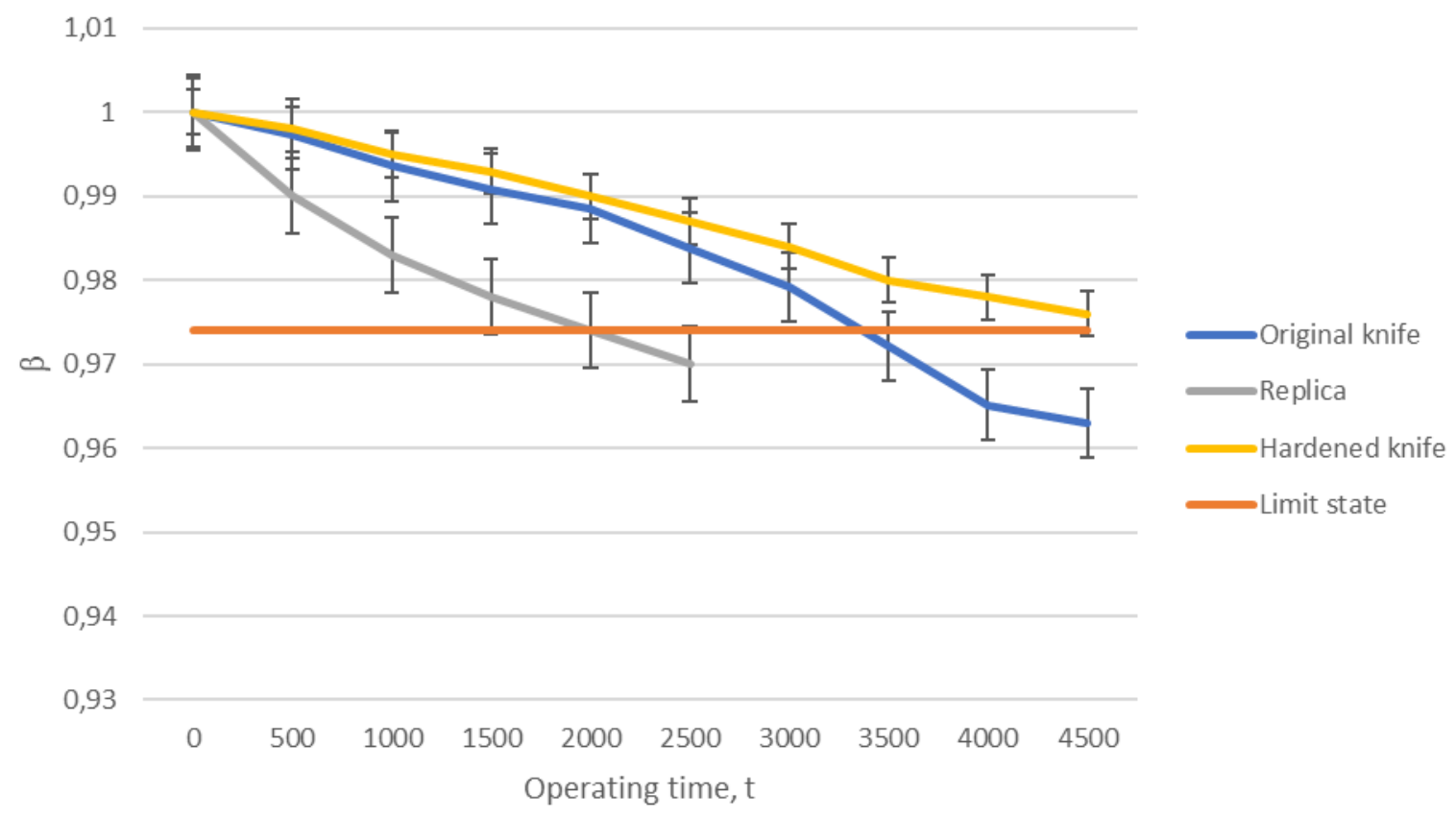

Fig. 6. Wear of the mixer knives

\section{Conclusions}

The technology of hardening the front surface of the feed mixer knife by the method of electrospark alloying has been investigated. The evaluation of the microhardness of the obtained coatings from various materials and in various modes of deposition has been carried out. The parameters of the technological process of coating deposition were selected to ensure the minimum porosity and sufficient microhardness of the hardening layer.

A study of the processes of wear of the knives of a feed mixer made of various materials and a hardened knife was carried out. It is shown that coating a knife with high-speed steel R6M5 allows to increase the resource of a knife made of cheap steel by $67 \%$ in comparison with the original highstrength knife.

\section{References}

[1] Krupin A.E. Calculation of reliability indicators for the DON-1500 B combine harvester. Krupin, E.A. Lisunov, A.A. Kalashov //Bulletin of the State Institute of Nuclear Power Engineering, 2018. No. 2 (81). pp. $42-53$

[2] Kolomeychenko A.V. Theory and practice of electrospark hardening of cutting parts of machines with amorphous and nanocrystalline alloys: textbook. monograph/A.V. Kolomeychenko, I.S. Kuznetsov. -Orel: Publishing House Orel GAU, 2015. 174 p. (In Russian).

[3] Penyashki T. Investigation of properties and wear of WC, TiC and TiN based multilayer coatings applied onto steels C45, 210CR12 and HS6-5-2 deposited by non-contact electrospark process /T. Penyashki, G. Kostadinov, I. Mortev, E. Dimitrova //Journal of the Balkan Tribological Association, 2017 .-Vol. 23. -No. 2. pp. 325 -342.

[4] Zhylinski V., Chayeuski V., Grishkevich A.A., Kuleshov A., Garanin V.I.. Hardening blade knife woodworking tools by using alternative methods of formation of Fe- and Mo-N-covers. 2013. DOI: $10.13140 /$ RG.2.1.4459.4803. 
[5] Balkhaya, Anhar M., Suwarno S., Sani S. (2019). Investigation of knife quality by using forging and flame hardening methods. IOP Conference Series: Materials Science and Engineering. 506. 012004. 10.1088/1757-899X/506/1/012004.

[6] Romanenko E. Yu., Vodolazskaya N. V. Engineering in modern construction. IOP Conference Series: Materials Science and Engineering, 1083 (1), 2021, pp. 012055, DOI: 10.1088/1757899X/1083/1/012055.

[7] Vodolazskaya N., Sharaya O. Modifying of the Surface of Products from Cast Iron as the Element of Production Modernization. Solid State Phenomena, vol. 299, 2020, pp. 588-593, DOI: 10.4028/www.scientific.net/SSP.299.588

[8] Vodolazskaya $\mathrm{N}$. Types and ways of modernization in a context of the international experience. Virtual Economics, Vol. 2. No 2(1), 2019, pp. 81-93, DOI: 10.34021/ve.2019.02.01(5)

[9] Vodolazskaya N., Sharaya O. Wear resistance of cast iron parts due to modification of surface layer. Journal of Advanced Research in Technical Science, Iss. 18, 2020, pp. 33-36, DOI: 10.26160/24745901-2020-18-33-36

[10]Zadorozhnyy R.N. Connecting rod restoration technology by combining electrospark treatment and cold gas-dynamic powder spraying. Machine-technological station. 2012. №6. pp. 45-49. (In Russian).

[11] Slobodyuk A. Strengthening of cultivator paws with electrospark doping/Alexey Slobodyuk, Sergey Strebkov, Andrey Bondarev, Andrey Sahnov // Engineering for rural development./ Proceedings, Vol 18, : Latvia University of Life Sciences and Technologies/- Jelgava, 2019pp. 549-554. ISSN 1691-5976, DOI: DOI: 10.22616/ERDev2019.18.N178. 